\title{
Regional Development of Orchardgrass Choke and Estimation of Seed Yield Loss
}

\author{
W. F. Pfender and S. C. Alderman, United Stated Department of Agriculture-Agricultural Research Service, Na- \\ tional Forage Seed Production Research Center, Corvallis, OR 97331
}

\begin{abstract}
Pfender, W. F., and Alderman, S. C. 2006. Regional development of orchardgrass choke and estimation of seed yield loss. Plant Dis. 90:240-244.

A survey for choke, caused by Epichloë typhina, in orchardgrass seed-production fields in Oregon was conducted annually from 1998 to 2003. In all, 99 fields were inspected, 57 in more than 1 year, to produce a set of 217 observations on disease incidence. There was a significant increase in disease incidence in 38\% of the revisited fields, and a significant reduction of incidence in $3 \%$. Yearly increases in disease incidence were as high as $29 \%$ in individual fields, but the average yearly increase from 1999 to 2003 was 5 to $8 \%$. In 1998, 60\% of all surveyed fields were infested with choke and, by $2003,90 \%$ were infested. Average disease incidence in fields in their first year of production was $<2 \%$, and average disease incidence in older fields was approximately $10 \%$, in 2003. Seed yield loss was equal to disease incidence (percentage of tillers diseased), and we found no significant yield compensation in diseased stands. An observed correlation of disease incidence with disease prevalence (proportion of sampled sites infested within a field) may permit simple estimation of incidence and, thus, of potential economic loss in an affected field. We estimate regional loss to the 2004 orchardgrass seed crop due to choke to be approximately $\$ 0.8$ million.
\end{abstract}

Additional keywords: Dactylis glomerata

Orchardgrass (Dactylis glomerata L.) is an important forage grass, and orchardgrass seed for pastures and hay in North America is produced almost exclusively in the Willamette Valley, OR. The pathogenic fungus Epichlö typhina (Pers.:Fr.) Tul. in Tul \& C. Tul., the causal agent of orchardgrass choke, was introduced into the Willamette Valley in the mid 1990s (1). Thereafter, it spread throughout the region by 1998 (8). Orchardgrass choke has been common in Europe for many years, and it was described in the 1950 s as having "long been indigenous" in Great Britain $(7,12)$.

Choke prevents inflorescence emergence and seed production on infected tillers, because the fungal stroma completely envelops 2 to $15 \mathrm{~cm}$ of the boot and the enclosed, developing inflorescence (6). Although it is possible for an inflorescence to partially escape entrapment by the stroma and produce a seed head of reduced size, this outcome is very rare and most symptomatic tillers produce no seed. The disease is monocyclic within a year but polyetic (can increase from year to year) in

Corresponding author: W. F. Pfender

E-mail: pfenderw@onid.orst.edu

Accepted for publication 6 September 2005.

DOI: 10.1094/PD-90-0240

This article is in the public domain and not copyrightable. It may be freely reprinted with customary crediting of the source. The American Phytopathological Society, 2006. the perennial orchardgrass seed fields (9). The year-to-year increase in infected tillers not only causes the levels of seed yield loss to increase in sequential years of production, but also limits the number of years a stand is profitable for production. At present, there are no measures for disease control or management other than stand removal and re-establishment, which is costly. Therefore, it is important to assess rates of yearly disease increase in commercial production and understand the relationship between disease incidence and yield loss.

In Great Britain (7), choke was rarely present in the first year of an orchardgrass stand but was present in 33 to $81 \%$ of the fields as stand ages increased from the second to fifth years of production, respectively. In addition, disease incidence in one of every four fields in the fourth year of production was 10 to $40 \%$. Reports from France $(4,10)$ indicated a similar yearly disease increase within affected orchardgrass stands, because choke rarely occurred in the first year of production but increased to $30 \%$ incidence by the fourth year.

The polyetic rate of disease increase likely is affected by a number of factors, some of which are poorly understood. The disease apparently spreads from plant to plant by means of spores (2), although the timing and nature of the infection process remain unresolved $(9,12)$. Once a plant is infected, the number of affected tillers increases from year to year $(3,11)$. Choke in orchardgrass apparently is not seed- borne (12). Rarely, a plant that is known to be infected has failed to express the disease in a subsequent year (11).

We previously reported polyetic rates of increase of approximately 9\% infected tillers per year in small, replicated test plots of orchardgrass (9). We also reported that, in the three fields where the disease initially was discovered in Oregon in 1997 , choke incidence increased from 13 to $35 \%$, 9 to $19 \%$, and 3 to $10 \%$, respectively, from 1997 to 1998 (8). It has been assumed, without direct measurement, that losses in seed production due to choke are equivalent to the proportion of tillers affected (7) and, on this basis, a nationwide loss of $3 \%$ for orchardgrass seed production was attributed to the disease in Great Britain in 1954. Large (7) found no evidence for compensation through increased tillering of infected plants, because the number of tillers per foot of row was constant regardless of choke incidence. However in a related pathosystem, E. bromicola affecting Bromus erectus, the number of inflorescences was inversely correlated with fungal infection (5). In the absence of yield loss measurements for orchardgrass choke, we decided that experiments to relate yield loss to choke incidence in this pathosystem were warranted.

One objective of this study was to determine the range of polyetic increase in commercial fields as well as the change in regional prevalence of orchardgrass choke since its introduction to Oregon in the 1990s. Another objective was to estimate economic loss due to the disease by combining an estimate of current incidence in commercial fields with a yield loss function derived from field experiments.

\section{MATERIALS AND METHODS}

Survey of choke incidence in commercial orchardgrass seed fields. A current list of orchardgrass seed production fields registered with the Oregon Seed Certification Service was obtained each year. Fields were selected arbitrarily from this list to represent the geographic range of orchardgrass seed production in the Willamette Valley of Oregon. Fifty-two fields were surveyed in 1998 (8). Fewer fields were surveyed in 1999 and 2000 (14 and 17 fields, respectively). In 2001, 2002, and 2003, we surveyed 42, 51, and 65 fields, respectively. Thus, the total number of field surveys was 217 . In each survey year, we included as many previously surveyed fields as possible, so that the number of different fields surveyed (99) was less than 
the total number of surveys. Of the surveys performed, 118 were repeat visits to fields that had been surveyed in at least one previous year. It was not possible to survey all fields in multiple years because some fields were taken out of production by growers. Sampling dates were: 12 to 27 June 1998, 20 to 25 June 1999, 22 to 23 June 2000, 13 to 26 June 2001, 10 to 27 June 2002, and 27 May to 6 June 2003. Locations of sampled fields are shown in Figure 1.

The method for sampling fields was as previously described (8). Briefly, 10 quadrats $\left(0.25 \mathrm{~m}^{2}\right.$ each $)$ were examined along each of four transects oriented diagonally to the field borders in each field. The number of tillers bearing stroma of E. typhina was counted in each quadrat to obtain 40 values for diseased tillers/ $/ 0.25$ $\mathrm{m}^{2}$ for each field. The total number of tillers $/ 0.25 \mathrm{~m}^{2}$ (healthy + diseased) was counted in an additional four to six randomly selected quadrats in each field. To convert the 40 observations/field to incidence (percent choked tillers), each value was divided by the estimate of total tillers per quadrat obtained by averaging the four to six counts of total tillers for that field. Change in the amount of choke over time within a field was analyzed by comparing the 40-observation means of choke incidence among the different years. Because the 40 data values from a field typically were not distributed normally, the nonparametric Mann-Whitney test in SigmaStat software (SPSS Inc., Chicago) was used for comparisons, with a critical $P$ value of 0.01 . Sampling variability was estimated by conducting the described measurements three times on the same field in 1 day, and testing for among-estimate variability. This procedure was done on a total of three fields selected to represent a range of choke incidences.

It is time-consuming to determine choke incidence as described; therefore, a relationship was sought between incidence and the more easily measured prevalence (percentage of quadrats in which choke was present, regardless of its amount). The prevalence and incidence observations from each of the 217 field surveys in the 6year data set were plotted, and Table Curve (Systat Software, Inc., Point Richmond, CA) was used to facilitate selection of an equation that best fit the data.

Yield loss relationship. Data for the relationship of seed yield to choke incidence was obtained from a 1997 planting of orchardgrass (cv. Takena) at the Hyslop Experiment Farm north of Corvallis, OR. The crop was planted with a $30-\mathrm{cm}$ row spacing in seven-row strips each $20 \mathrm{~m}$ long, with a 1-m alley between strips. Choke developed irregularly within the planting. On 26 June 2001 and 30 June 2002, arbitrarily selected samples of the planting were harvested. There were 10 samples in
2001 and 17 in 2002. Each sample consisted of a 1-m-wide swath cut perpendicular to the rows across a seven-row strip. In each sample, the numbers of choked tillers and healthy heads were counted. The incidence (percentage) of choke in each sample was calculated as the number of choked tillers divided by the sum of the choked tillers plus healthy seed-producing heads. After harvest, the healthy seed heads were allowed to dry for 1 week in burlap bags hanging from a drying line outdoors. The seed weights per sample were determined after threshing and clean- ing each sample individually and drying the seed to constant moisture content, determined by weight. Linear regression analysis was used to determine the relationship between seed yield and percent tillers with choke. In addition, we used regression analysis to test for yield compensation, which would be indicated by an increase in number of tillers or seed yield per healthy seed-head with an increase in disease incidence. Regression analyses were conducted with SigmaStat software (SPSS Inc.) for the data from each year individually.

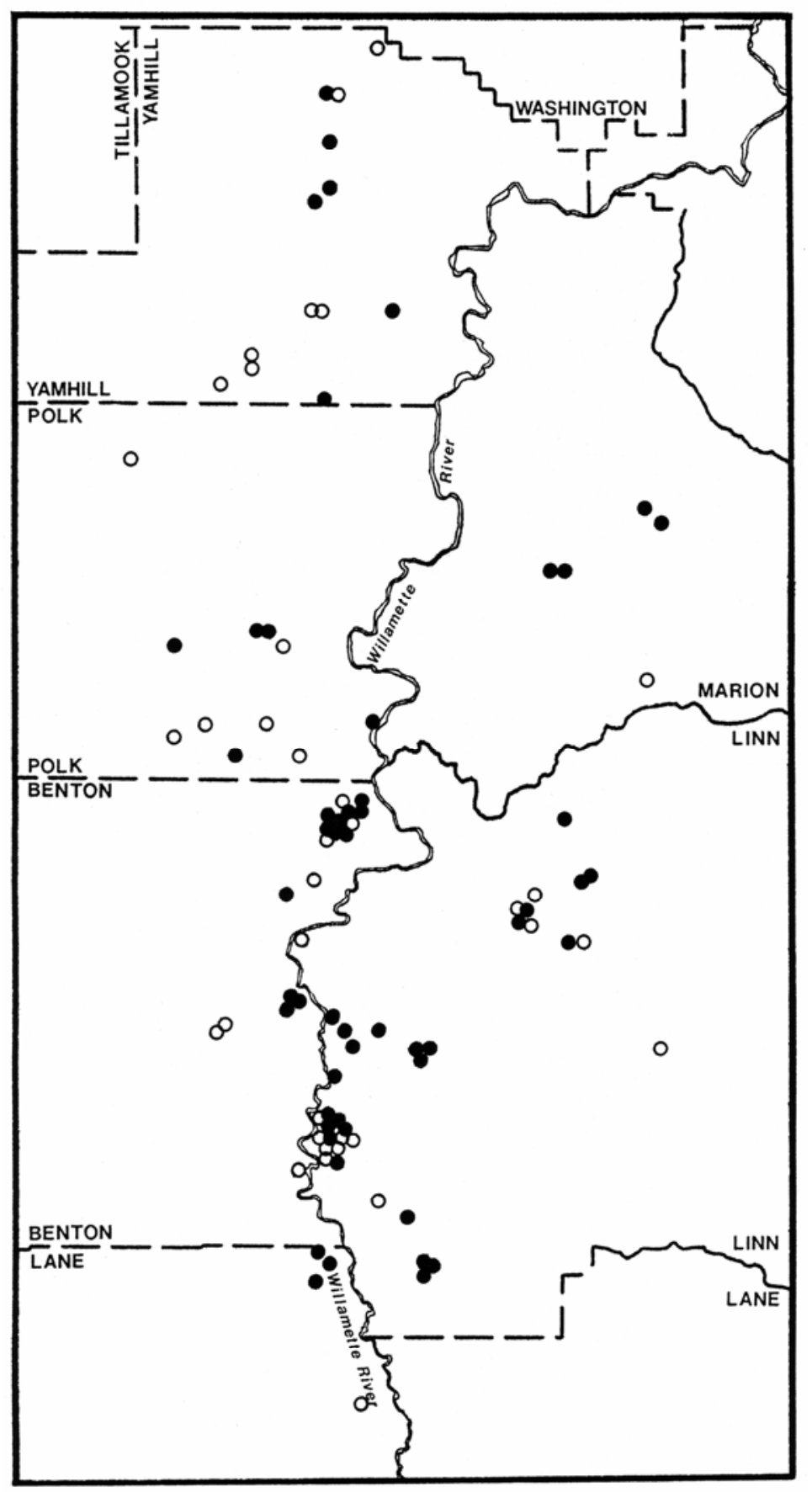

Fig. 1. Locations of orchardgrass fields in the Willamete Valley, OR, surveyed for choke from 1998 to 2003. Open circles represent the 42 fields surveyed once and closed circles indicate the 57 fields surveyed in more than 1 year. The mapped area is 105 by $200 \mathrm{~km}$, and its center is approximately $44.75^{\circ} \mathrm{N}, 123.17^{\circ} \mathrm{W}$. 


\section{RESULTS}

Occurrence and increase of choke in commercial fields. In each year of the survey, most fields had choke (Table 1). Disease incidence (percent tillers diseased) ranged from 0 to $55.9 \%$ among the 217 observations, with a mean incidence of $6.2 \%$. The lowest quartile of the 217 disease incidence values ranged from 0 to $0.2 \%$ and the upper quartile ranged from 8.5 to $55.9 \%$. Fields with over $25 \%$ incidence commonly were taken out of production.

Of 99 fields included in the survey, 57 were visited in more than 1 year. In 41 of the revisited fields, there was a significant increase in disease for at least one of the yearly intervals. In contrast, there was a significant decrease in 3 of these fields, and no significant change in 13. Analysis of change in incidence in all 118 annual revisits, including multiple revisits to the same field over several years, showed a significant $(P<0.01)$ disease increase in 45 of the cases, a significant decrease in 3 , and no statistically significant change in 70 of the revisits (Table 2). Maximum 1-year increases of $>15 \%$ choked tillers were observed in 10 of the repeat visits whereas, in the other 35 repeated visits with significant increases, the increments ranged from 6 to $14 \%$. In nine of the fields where there was no significant change in choke incidence, the incidence was already greater than $5 \%$ in the first observation of the series.

On average, orchardgrass fields planted in 1998 or 1999 reached approximately $10 \%$ incidence in their third year of production, but the average disease incidence in fields planted in 2001 reached this level in their second year (Fig. 2). We did not observe a clear progression of disease incidence with stand age in fields planted prior to 1998. When disease incidence was averaged by stand age within each year, there were marked differences among stand ages in the early years following pathogen introduction (Fig. 3). By 2003, however, the average percent choke incidence was approximately $10 \%$ in stands older than 1 year. Average disease incidence in first-year fields was 0 to $0.25 \%$ from 1998 to 2001 , but was 1.4 and $0.8 \%$ in 2002 and 2003.

The proportion of fields containing choke increased from $62 \%$ in 1998 to approximately $90 \%$ by 2000 , and remained at that level through 2003 (Fig. 4). From 1998 to 2003, the prevalence of choke within affected fields, as measured by the proportion of $0.25-\mathrm{m}^{2}$ quadrats containing diseased tillers, increased from 40 to $65 \%$ (Table 1). The proportion of all surveyed quadrats in the production area (including those in nonaffected fields) containing diseased tillers increased from 25 to $59 \%$ during the same period (Table 1). Among the approximately 100,000 choked tillers we counted during the 6 years of this study, we noted fewer than 10 partially choked heads. In the great majority of cases, a tiller with any visible choke disease was completely blocked from producing seed.

Prevalence of choke (percent quadrats containing choked tillers) ranged from 0 to $100 \%$ in individual fields, and the frequency of fields with prevalence $>75 \%$ increased between 1998 and 2003 (Table 1). In the data set of 217 observations, disease incidence (percent tillers diseased) was correlated with prevalence (Fig. 5). The relationship was best described by a power function, based on simplicity of the model, $r^{2}$, and lack of pattern in the residuals. A prevalence of $75 \%$ corresponded to an incidence of approximately $9.4 \%$.

The validity of the field sampling procedure was evaluated by conducting three of the 40-quadrat assessments on the same field in the same day and testing for significant difference among the assessments. This approach was applied to three different fields. For each of the fields, there was no significant difference among the three assessments with respect to the estimates for disease incidence (percent tillers diseased). The $P$ values for comparisons within each of the three fields were 0.97 , 0.07 , and 0.09 . Note that the $P$ value used for declaring significant difference in the survey results was 0.01 .

Yield loss due to choke. Incidence of choke in field plots ranged from 8 to $66 \%$ diseased tillers in the 2001 experiment and from 11 to $65 \%$ in the 2002 experiment. No partially choked heads were observed; therefore, disease incidence represents the proportion of seed heads prevented from producing any seed. Seed yield from the $2.1-\mathrm{m}^{2}$ plots ranged from 70 to $325 \mathrm{~g}$ $($ mean $=190 \mathrm{~g}$, standard error $=26.4)$ and from 91 to $320 \mathrm{~g}$ (mean $=172 \mathrm{~g}$, standard error $=14.0)$ in 2001 and 2002, respectively. In each year, there was a significant linear relationship between percent diseased tillers and seed yield. Regression equations for 2001 and 2002 data were $y=$

Table 2. Change in incidence of orchardgrass choke in fields that were assessed in more than 1 year

\begin{tabular}{lcccc}
\hline & & \multicolumn{3}{c}{ No. of fields in indicated category of change } \\
\cline { 2 - 5 } Year of observation & No. of fields $^{\mathbf{b}}$ & Increase & No change & Decrease $^{-}$ \\
\hline 1999 & 6 & 1 & 5 & 0 \\
2000 & 9 & 1 & 7 & 1 \\
2001 & 19 & 10 & 9 & 0 \\
2002 & 35 & 10 & 25 & 0 \\
2003 & 49 & 23 & 24 & 2 \\
\hline
\end{tabular}

${ }^{a}$ Disease incidence (percent tillers with choke) in the indicated year for each field was compared with the incidence observed in that field's previous survey. Change is indicated as a significant $(P<0.01)$ increase or decrease, or no significant change, based on the Mann-Whitney test.

${ }^{\mathrm{b}}$ Number of fields surveyed in the indicated year that also were surveyed in at least 1 previous year.

Table 1. Frequency distribution of choke in orchardgrass seed fields in Oregon, 1998 to 2003

\begin{tabular}{|c|c|c|c|c|c|c|c|c|c|}
\hline \multirow[b]{2}{*}{ Year } & \multicolumn{2}{|c|}{ Number of fields } & \multirow[b]{2}{*}{ Observation scale } & \multicolumn{6}{|c|}{ Number of fields with designated level of incidence, by quadrat or field ${ }^{a}$} \\
\hline & Surveyed & Infested $^{b}$ & & $\mathbf{0 \%}$ & $1-10 \%$ & $11-25 \%$ & $26-50 \%$ & $51-75 \%$ & $76-100 \%$ \\
\hline \multirow[t]{2}{*}{1998} & 52 & 32 & Quadrats within fields & 20 & 9 & 6 & 5 & 5 & 7 \\
\hline & & & Field averages & 20 & 28 & 3 & 1 & 0 & 0 \\
\hline \multirow[t]{2}{*}{1999} & 14 & 10 & Quadrats within fields & 4 & 2 & 2 & 2 & 2 & 2 \\
\hline & & & Field averages & 4 & 8 & 1 & 1 & 0 & 0 \\
\hline \multirow[t]{2}{*}{2000} & 17 & 16 & Quadrats within fields & 1 & 3 & 4 & 1 & 6 & 2 \\
\hline & & & Field averages & 1 & 14 & 2 & 0 & 0 & 0 \\
\hline \multirow[t]{2}{*}{2001} & 42 & 37 & Quadrats within fields & 5 & 1 & 3 & 8 & 12 & 13 \\
\hline & & & Field averages & 5 & 31 & 6 & 0 & 0 & 0 \\
\hline \multirow[t]{2}{*}{2002} & 51 & 47 & Quadrats within fields & 4 & 7 & 6 & 9 & 12 & 13 \\
\hline & & & Field averages & 4 & 34 & 11 & 1 & 1 & 0 \\
\hline \multirow[t]{2}{*}{2003} & 65 & 58 & Quadrats within fields & 7 & 4 & 4 & 9 & 16 & 25 \\
\hline & & & Field averages & 7 & 36 & 19 & 3 & 0 & 0 \\
\hline
\end{tabular}

a In each field surveyed, 40 quadrats (each $0.25 \mathrm{~m}^{2}$ ) were sampled and the percentage of tillers with choke symptoms was determined in each quadrat. The 40 values per field were averaged to produce the estimate of incidence at the field level. Table entries are the number of fields in each category of disease incidence, whether as percent quadrats with disease present or as the overall field average for incidence.

${ }^{\mathrm{b}}$ Number of the surveyed fields in which choke was present at any level. 
$-2.93 x+293.6\left(r^{2}=0.58, P=0.011\right)$ and $y$ $=-2.56 x+259.6\left(r^{2}=0.50, P=0.001\right)$, respectively, where $y=$ yield and $x=$ percent choke. That is, for disease incidence between 8 and $65 \%$, each $1 \%$ increase in choke is correlated to a $1 \%$ reduction in the yield estimated for $0 \%$ disease (the $y$ intercept; Fig. 6A). There was no evidence for significant yield compensation by the decreasing number of healthy seed heads in increasingly diseased plots (Fig. 6B). The regression equation for yield per healthy tiller $(y)$ versus disease incidence $(x)$ in 2001 was $y=0.0017 x+0.374\left(r^{2}=0.03\right.$, $P=0.29)$. For the 2002 data, the equation was $y=0.007 x+0.374\left(r^{2}=0.00, P=\right.$ 0.62 ). Nor was there significant compensation via an increased number or tillers being produced from diseased plants (Fig. 6C). The regression equations for number of tillers $(y)$ versus choke incidence $(x)$ in 2001 and 2002 were, respectively, $y=-2.55 x+$ $769.4\left(r^{2}=0.06, P=0.24\right)$ and $y=-0.242 x$ $+684.0\left(r^{2}=0.00, P=0.91\right)$.

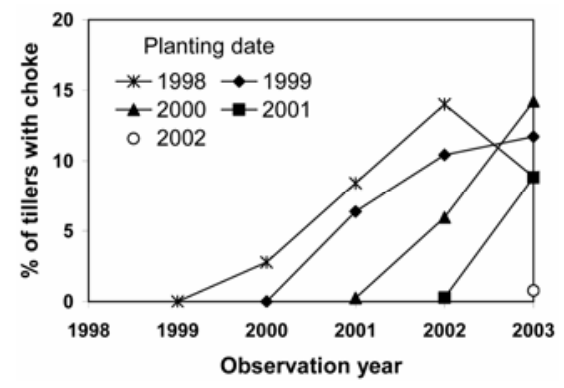

Fig. 2. Levels of choke in commercial orchardgrass seed-production fields surveyed annually in Oregon. Each data point is the average for six to nine fields of the indicated planting date in each observation year. The graphed data, a subset of the data summarized in Table 2, include only fields that were sampled annually from the first year of seed production.

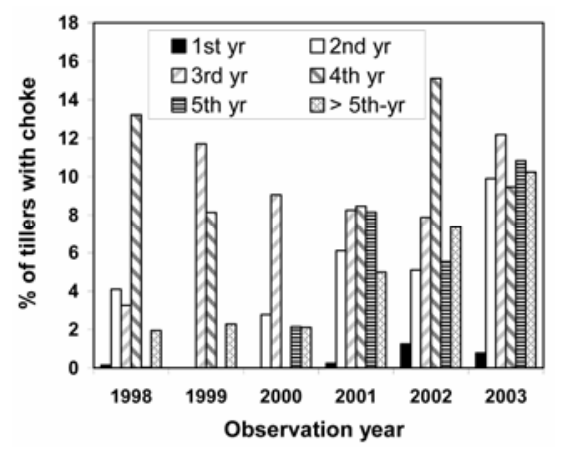

Fig. 3. Average incidence of choke in orchardgrass seed-production fields surveyed from 1998 to 2003, categorized by stand age in the year of observation. There were no observations for second- and fifth-year stands in 1999 or for fourth-year stands in 2000. The percent choked tillers value for each field was calculated from 40 quadrat counts of the number of diseased tillers, each divided by the number of total tillers (diseased plus healthy) per quadrat, as determined from four to six randomly selected quadrats in the field.
Loss of orchardgrass seed yield due to choke in the Willamette Valley region was estimated from the loss function described in the previous paragraph, combined with an analysis of disease incidence in the production fields. Because choke incidence depends on stand age (Fig. 3), regional disease incidence estimates require information about frequency distribution for stand age. We obtained summary statistics for hectareage of certified orchardgrass seed fields from the Oregon State University Seed Certification Service. For the 2004 harvest year, $15.5 \%$ of the certified orchardgrass acreage was in its first year of production. From our measurements of disease incidence as a function of stand age (Fig. 3), we estimated that this acreage had an average disease incidence of $0.8 \%$, and that the remaining $84.5 \%$ of the certified acreage had an average disease incidence of $10.5 \%$. These calculations $(0.008 \times 0.155)+$ $(0.105 \times 0.845)$ produce an overall estimate of $9.0 \%$ disease incidence in the certified crop and, therefore, a $9.0 \%$ seed yield loss.

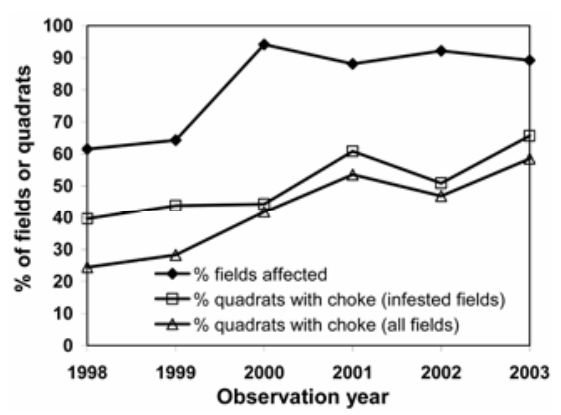

Fig. 4. Prevalence of choke in commercial orchardgrass seed-production fields in Oregon, 1998 to 2003. Field prevalence (percent fields affected) indicates the proportion of fields in the survey in which at least 1 choked tiller was observed. Quadrat-level prevalence is the number of $0.25-\mathrm{m}^{2}$ quadrats containing at least one choked tiller as a proportion of all quadrats sampled in the infested fields in the study or as a proportion of all quadrats sampled in the survey (including the 40 nondiseased quadrats in each nonaffected field).

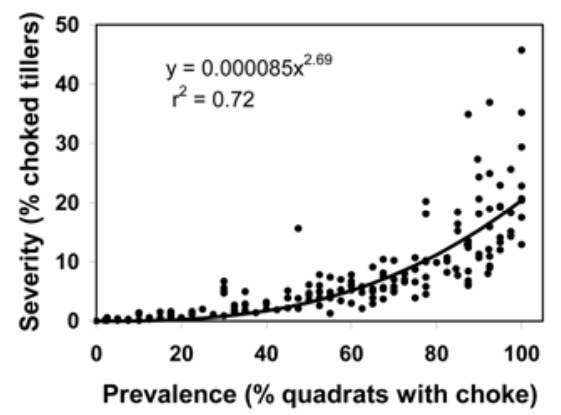

Fig. 5. Relationship between prevalence (percent quadrats with choke) and corresponding incidence (percent tillers with choke) in each of 217 assessments of commercial orchardgrass seed-production fields in Oregon, 1998 to 2003. Each point represents one field in one observation year.

\section{DISCUSSION}

The survey data reported here show that orchardgrass choke, caused by E. typhina, is now endemic and ubiquitous in the Willamette Valley of Oregon, the principal seed-production region for orchardgrass in North America. Since 2000, approximately $90 \%$ of the fields have been affected each year (Fig. 4). The unaffected $10 \%$ corresponds approximately to the proportion of acreage that is in the first year of production, when choke is relatively uncommon. Most fields older than 1 year, however, are now affected to some degree. In 1998, $32 \%$ of fields older than 1 year were free of choke, whereas only 1 to $2 \%$ of the fields in this category were free of choke in 2002 and 2003. Even several first-year fields were affected in 2002 and 2003, and one of the new fields surveyed in 2003 had an incidence of $6.3 \%$ choked tillers.

Reports from France and Great Britain show average incidence increasing steadily with stand age $(4,7)$. In the first few years of our survey (1998 to 2000), shortly after the disease was confirmed in 1997, there was no clear pattern of disease incidence associated with stand age. This difference between the North American and European reports probably reflects the recent introduction of the disease to Oregon, its occur-
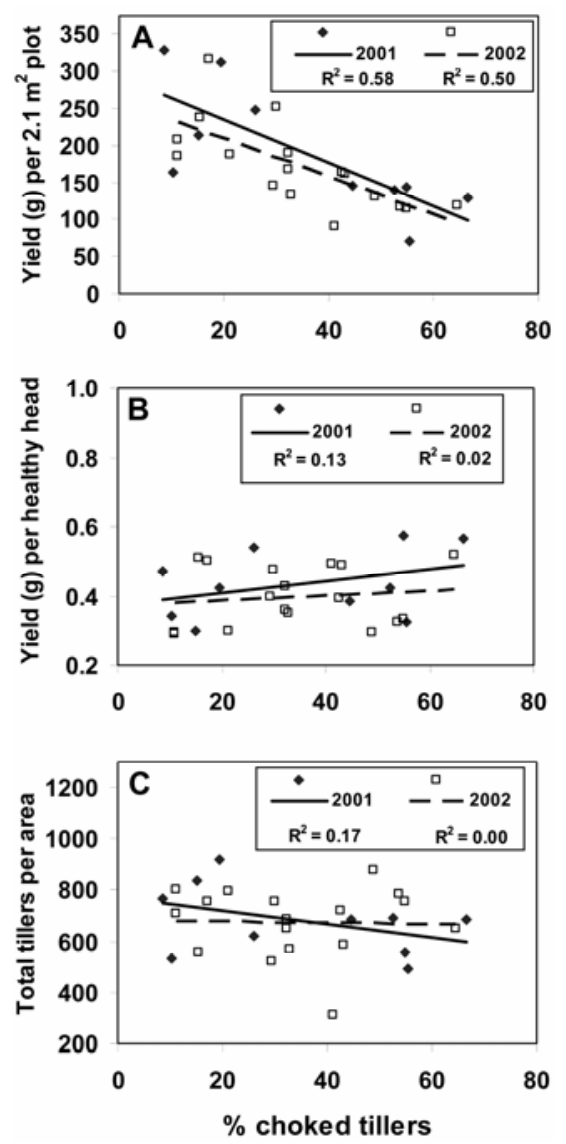

Fig. 6. Relationship between percent choked tillers per plot and A, yield per $2.1-\mathrm{m}^{2}$ plot, $\mathbf{B}$, yield per healthy head, or $\mathbf{C}$, total tillers per plot. The experiment was conducted in 2001 and 2002. See text for regression equations. 
rence at high levels in fields of various ages near the points of introduction, and its initial absence or rarity elsewhere in the region. By 2003, we observed the clear distinction in incidence between first-year and older fields. The fact that the average incidence is similar among all stands older than 1 year may reflect the removal of stands from production when the incidence reaches a threshold level that prompts grower action. The observation that disease incidence in our data set was not well correlated with stand age in fields planted prior to 1998 can be explained by the fact that our sample fields included some that were taken out of production after a year when they were severely diseased; this may have lowered the mean level of choke. Yearly rates of increase of choke within individual fields are currently 5 to $8 \%$ additional diseased tillers per year, with some instances of a yearly increase as high as $20 \%$ and other cases of insignificant increase. We noted rare instances of a significant decline in choke incidence from one year to the next. The apparent decrease in average percent choke for 1998-planted fields between 2002 and 2003 (Fig. 2) was due to a steep decline in incidence for two fields. We do not have an explanation for the differing rates of increase in different fields, despite attempts through interviews with growers to determine the differences in production practices that might be correlated with different rates of choke increase. We noted that several of the fields with a significant decline in disease also showed general signs of plant stress expressed as a thin stand. Volunteer seedlings in an infected stand could reduce the number or proportion of choked tillers if the new (and typically noninfected) plants replace older, less-vigorous, infected plants. Although the general practice is to maintain healthy established plants and to control volunteer orchardgrass seedlings with herbicide applications, it is possible that management choices in these unusual fields resulted in replacement of infected plants with noninfected ones. Also, it has been reported previously that plants known to be infected with E. typhina occasionally can fail to express the disease in a year subsequent to its initial observation (11).

Other researchers $(4,7)$ have suggested without data that yield loss could be directly equivalent to choke incidence, and we confirm in this report that seed yield loss can be equated with the percentage of tillers that are symptomatic (Fig. 6A). Because a diseased tiller is almost invariably completely prevented from producing seed, the incidence of diseased tillers is also a measure of disease severity in the field. In equating loss with incidence, we assume that the same relationship we observed for disease incidence of 8 to $65 \%$ holds also for incidence below $8 \%$. We consider this assumption to be justified, because we found no evidence for significant yield compensation, in either number of tillers produced or seed yield per healthy head, in the presence of the disease (Fig. 6B and C). Regional loss estimates can be computed by multiplying the average incidence for a given stand age by the proportion of the planted area that is of that age. We used data on the distribution of stand ages in the certified-seed production acreage in Oregon to compute a $9.0 \%$ loss in the 2004 crop. The certified hectareage (4,255 ha) represented $56 \%$ of the total area of orchardgrass seed production in Oregon in 2004 (Oregon State University Extension Service estimates). Noncertified fields are likely to stay in production longer than certified fields because of reduced stringency in standards for cultivar type and field appearance in noncertified fields; therefore, the noncertified crop area is likely to have a higher proportion of older ( $\geq 2$ years) fields than does the certified area. Therefore, applying the yield loss estimate of a certified production area to the noncertified area would be a conservative estimate of loss. Farm gate value (certified plus noncertified) of Oregon orchardgrass seed in 2004 was \$9.11 million; therefore, a yield loss of $9.0 \%$ represents $\$ 820,000$ of loss due to orchardgrass choke in 2004.

Prevalence of choke is now very high (Fig. 4) in Oregon, the major orchardgrass seed-producing region of North America. Given this prevalence, and the abundance of windborne ascospores that are discharged from the stroma of E. typhina (10), inoculum of the pathogen undoubtedly will be abundant over the growing region each year. Our data suggest that we can expect average disease incidence of at least $10 \%$ from the second year of production onward for seed fields. Our confirmation of the equivalence between incidence and yield loss will enable individual growers to make appropriate decisions about the economic consequences of maintaining or removing a stand infested with $E$. typhina.
Precise estimates of percent disease incidence are quite time-consuming, but incidence can be estimated from prevalence within a field (Fig. 5). Although prevalence becomes a poor predictor for incidence as the upper boundary of $100 \%$ prevalence is approached, prevalence may be useful for making a decision regarding stand removal or maintenance if a grower's economic threshold for yield loss is at or below approximately $10 \%$.

\section{ACKNOWLEDGMENTS}

We thank B. Matson for technical assistance.

\section{LITERATURE CITED}

1. Alderman, S. C., Pfender, W. F., Welty, R. E., Mellbye, M. E., Cook, R. L., Spatafora, J. W., and Putnam, M. 1997. First report of choke, caused by Epichloë typhina, on orchardgrass in Oregon. Plant Dis. 81:1335.

2. Chung, K. R., and Schardl, C. L. 1997. Sexual cycle and horizontal transmission of the grass symbiont, Epichloë typhina. Mycol. Res. 101:295-301.

3. Emecz, T. I., and Jones, D. G. 1970. Effect of gibberellic acid on inflorescence production in cocksfoot plants infected with choke (Epichloë typhina). Trans. Br. Mycol. Soc. 55:77-82.

4. Fermaud, M. 1986. Epidémiologie de la quenouille du dactyle porte-graine due a Epichloë typhina (Pers. Ex Fr.) Tulasne. Ph.D. thesis, Ecole Nationale Supérieure Agronomique de Montpelier, France.

5. Groppe, K., Steinger, T., Sanders, I., Schmid, B., Wiemken, A., and Boller, T. 1999. Interaction between the endophytic fungus Epichloë bromicola and the grass Bromus erectus: effects of endophyte infection, fungal concentration and environment on grass growth and flowering. Mol. Ecol. 8:1827-1835.

6. Kirby, E. J. M. 1961. Host-parasite relations in the choke of grasses. Trans. Br. Mycol. Soc. 44:493-503

7. Large, E. C. 1954. Surveys for choke (Epichloë typhina) in cocksfoot seed crops 1951-1953. Plant Pathol. 3:6-11.

8. Pfender, W. F., and Alderman, S. C. 1999. Geographical distribution and incidence of orchardgrass choke, caused by Epichloë typhina, in Oregon. Plant Dis. 83:754-758.

9. Pfender, W. F., and Alderman, S. C. 2003. Evaluation of postharvest burning and fungicides to reduce the polyetic rate of increase of choke in orchardgrass seed production. Plant Dis. 87:375-379.

10. Raynal, G. E. 1991. Libération des ascospores d'Epichloë typhina, agent de la quenouille du dactyle: Consequences pour l'épidémiologie et la lutte. Fourrages 127:345-358.

11. Sampson, K. 1933. The systemic infection of grasses by Epichloë typhina (Pers.) Tul. Trans. Br. Mycol. Soc. 18:30-47.

12. Western, J. F., and Cavett, J. J. 1959. The choke of cocksfoot (Dactylis glomerata) caused by Epichloë typhina (Fr.) Tul. Trans. Br. Mycol. Soc. 42:298-307. 